CASE REPORT

\author{
K. Obeng \\ Z. Rumboldt \\ G. Tuite \\ C.T. Welsh \\ S. Patel \\ M.V. Spampinato
}

\section{Atypical Cystic Meningioma of the Trigeminal Nerve in a Pediatric Patient}

SUMMARY: We report an unusual case of atypical cystic meningioma of the trigeminal nerve proved by histology in a 15-year-old white girl. A review of the literature showed that this is only the second reported case of a meningioma of the trigeminal nerve without dural attachment and the first occurrence in a pediatric patient.
$\mathbf{P}$ rimary tumors of the trigeminal nerve and Meckel cave represent less than $0.5 \%$ of intracranial tumors. ${ }^{1}$ We report the case of a dumbbell-shaped atypical meningioma of the trigeminal nerve without dural attachment, involving the Meckel cave and the posterior fossa in an adolescent.

\section{Case Report}

A 15-year-old white girl presented with a 2-month history of leftsided facial numbness and loss of sensation of the left hemitongue. Physical examination showed hypoesthesia in the left V1, V2, and V3 dermatome distribution and absent left corneal reflex. She had no family history of neurofibromatosis, and physical examination revealed no evidence of café au lait spots or freckling in the axillary or inguinal area. Aside from the absence of a left corneal reflex, the findings of the ophthalmologic examination were unremarkable, with no evidence of lens abnormalities.

A brain MR imaging revealed an extra-axial dumbbell-shaped cystic mass, without obvious "dural tail" or dural attachment, demonstrating peripheral rim enhancement (Fig 1), with a cystic component in the posterior fossa at the root entry zone of the left trigeminal nerve, and a second cystic lesion with a fluid-fluid level at the level of the left Meckel cave. The mass was thought to be consistent with a cystic schwannoma of the left trigeminal nerve. There were no masses along the course of the 8 cranial nerves.

A 1-stage surgical excision of the middle and posterior fossa components of the mass was planned. The patient underwent a left-sided skull base craniotomy, with a left temporal craniotomy and zygomatic osteotomy, by using an extradural approach. At surgery, it was noted that the mass arose from the left trigeminal nerve, did not have a dural attachment, and was heavily intermixed with the surrounding trigeminal nerve. Surgical resection of the mass was thought to be complete.

The resected gross specimen consisted of multiple fragments of brown-red variegated tissue. Histology (Fig 2) showed concentric structures typical of meningioma, hypercellularity, mitotically active foci, and focal necrosis, making it atypical. Embedded nerve fascicles of the excised trigeminal nerve appeared infiltrated by tumor. Reticulin stain showed chiefly perivascular staining in the tumor, highlighting its vascularity. A final diagnosis of atypical meningioma was made.

Given the histology and the location of the neoplasm, we planned

Received July 26, 2006; accepted after revision October 2.

From the Departments of Radiology (K.O., Z.R., M.V.S.), Neurosurgery (G.T., S.P.), and Pathology (C.T.W.), Medical University of South Carolina, Charleston, SC.

Please address correspondence to Maria Vittoria Spampinato, MD, Department of Radiology, Medical University of South Carolina, Radiology, 169 Ashley Ave, P0 Box 250322, Charleston, SC 29425; e-mail: spampin@musc.edu

DOI 10.3174/ajnr.A0876 to treat residual or recurrent tumor with stereotactic radiosurgery. Since surgery, a postoperative MR imaging and subsequent follow-up MR imaging performed every 2 months in the last 4 months did not demonstrate evidence of macroscopic residual or recurrent tumor. Findings of an MR imaging of the cervical spine performed 2 months after surgery were normal, with no evidence of intra- or extradural masses.

\section{Discussion}

Approximately one third of all primary tumors of the Meckel cave are schwannomas, with the remainder consisting of meningiomas, epidermoids, dermoids, lipomas, metastases, hemangiomas, and lymphomas. ${ }^{1,2}$ Although very few pediatric cases of trigeminal schwannomas have been reported in the literature, ${ }^{3,4}$ to our knowledge, this is the first case of an atypical meningioma along the trigeminal nerve in a pediatric patient.

Meningiomas of the Meckel cave are rare and account for approximately $1 \%$ of all intracranial meningiomas. ${ }^{5,6}$ The Meckel cave is a dural recess in the posterior medial portion of the middle cranial fossa, containing the trigeminal ganglion. Meningiomas of the Meckel cave typically originate from the dura mater, compress the trigeminal ganglion, and can extend toward the middle cranial fossa or through the porus trigeminus into the posterior fossa in a dumbbell-shaped configuration. $^{2}$

Meningiomas generally derive from dural-based arachnoid cap cells; however, intracranial meningiomas without dural attachment occur in the ventricles, Sylvian fissure, pineal region, and even in the brain parenchyma. ${ }^{7}$ The average age at diagnosis of patients affected by meningiomas without dural attachment is 26.5 years, approximately 20 years younger than the average age at diagnosis of meningiomas in general, with a male-to-female ratio of meningiomas without dural attachment of 1.39:1. ${ }^{7}$ The diagnosis of meningioma at an early age should raise the possibility of neurofibromatosis type 2. Our patient did not fulfill the diagnostic criteria for neurofibromatosis type 1 or $2 .^{8}$

Atypical meningiomas (World Health Organization grade II/IV) exhibit a more aggressive behavior and an increased risk of recurrence after treatment. ${ }^{9}$ Most of the previously reported atypical meningiomas without dural attachment were intraventricular, with the exception of a single case of intraparenchymal atypical meningioma in a 16 -year-old boy. ${ }^{7}$ A review of the literature yielded a single documented case of trigeminal nerve meningioma without attachment to the dura in a 69year-old woman, but this lesion had no atypical features. ${ }^{10}$ 

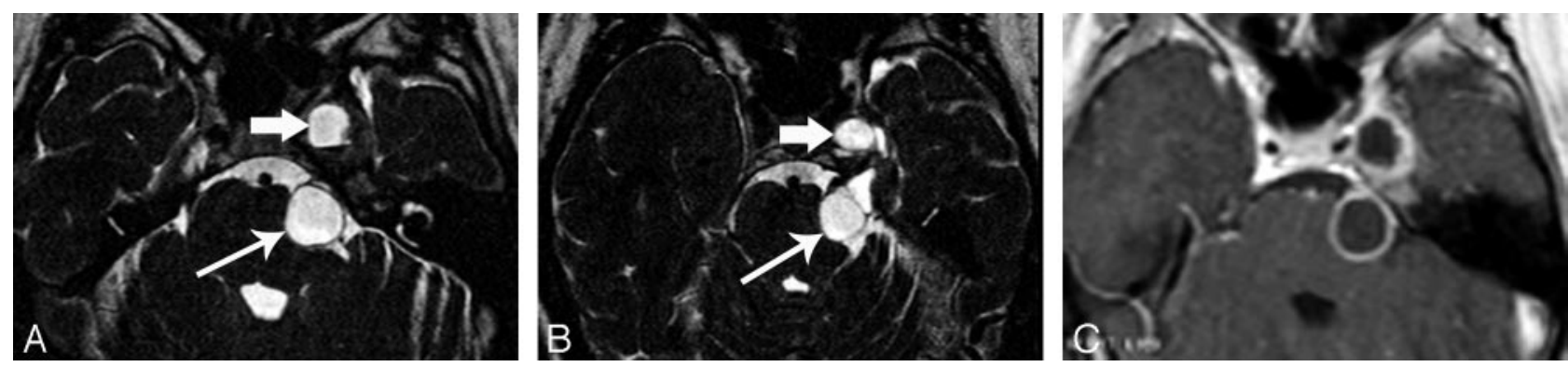

Fig 1. $A-C$, Axial T2-weighted $(A$ and $B)$ and axial postcontrast T1-weighted $(C)$ images demonstrate a dumbbell-shaped extra-axial mass in the Meckel cave (short arrows) and in the left prepontine cistern (long arrows).
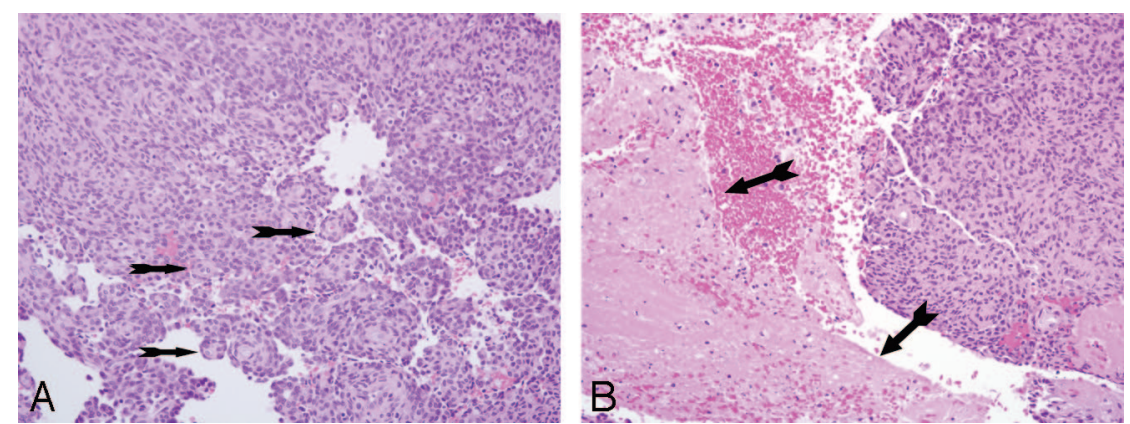

Fig 2. A, The concentric structures (arrows) typical of a meningioma are depicted. Small round-to-oval nuclei with inconspicuous nucleoli are present (hematoxylin-eosin [HE] stain, original magnification $\times 20$ ). $B$, Necrosis (arrows) is also a prominent feature (HE stain, original magnification $\times 20)$.
In our paitent and in the case previously described by Fujimoto et al, ${ }^{10}$ the tumor most likely originated from arachnoid cap cells within the left trigeminal nerve sheath or from the perineural cells of the nerve and not from the dura of the Meckel cave. ${ }^{10}$ In both cases, the trigeminal nerve meningiomas had a cystic appearance and involved the cisternal portion of the nerve and Meckel cave. Therefore, meningiomas of the trigeminal nerve, though rare, should be included in the differential diagnosis of cystic dumbbell-shaped trigeminal nerve tumors. To our knowledge, this is the first reported atypical meningioma originating from the trigeminal nerve in a pediatric patient and the second documented case of a meningioma without dural attachment arising from the trigeminal nerve.

\section{References}

1. Yuh WT, Wright DC, Barloon TJ, et al. MR imaging of primary tumors of trigeminal nerve and Meckel cave. AJR Am J Roentgenol 1988;151:577-82
2. Kapila A, Chakeres DW, Blanco E. The Meckel cave: computed tomographic study. Part I. Normal anatomy. Part II. Pathology. Radiology 1984;152:425-33

3. Ross DL, Tew JM Jr, Benton C, et al. Trigeminal schwannoma in a child. Neurosurgery 1984;15:108-10

4. Verstappen CC, Beems T, Erasmus CE, et al. Dumbbell trigeminal schwannoma in a child: complete removal by a one-stage pterional surgical approach. Childs Nerv Syst 2005;21:1008-11. Epub 2005 Mar 16

5. Butti G, Gaetani P, Giordana MT, et al. Meningiomas of Meckel cave. Surg Neurol 1983;20:305-09

6. Delfini R, Innocenzi G, Ciappetta P, et al. Meningiomas of Meckel cave. Neurosurgery 1992;31:1000-06, discussion 1006-07

7. Zhang J, Chi LY, Meng B, et al. Meningioma without dural attachment: case report, classification, and review of the literature. Surg Neurol 2007;67:535-39

8. Neurofibromatosis. Natl Inst Health Consens Dev Conf Consens Statement 1987;6:1-7

9. Louis D, Scheithauer B, Budka H, et al. Pathology and Genetics of Tumours of the Nervous System. Lyon, France: IARC Press; 2000:175-95

10. Fujimoto $\mathrm{Y}$, Kato A, Taniguchi M, et al. Meningioma arising from the trigeminal nerve: a case report and literature review. J Neurooncol 2004;68:185-87 